\title{
A CONSTITUIÇÃO DO DISCURSO FORMAL NO TRIBUNAL DO JÚRI
}

\author{
(The constitution of formal discourse in a trial court)
}

\author{
Cibele Brandão ${ }^{1}$ \\ (Universidade de Brasília- UnB) \\ Wanderson Melo 2 \\ (Universidade de Brasília- UnB)
}

\begin{abstract}
We aimed to analyze the constitution of formal discourse in a trial court so as to set up its constitutive parameters based upon the speeches given by prosecutors and defense attorneys. The very choice of this scenario can be explained due to the accomplishment of several formal rules of procedures taken in this place. It is a qualitatively oriented research built on interactional sociolinguistics with ethnographic orientation, coupled up with oral speech analysis. To this end, a video-recording session was carried out at the Federal District Court, comprising approximately 11 hours.
\end{abstract}

Keywords: formality, judicial discourse, trial court

\section{RESUMO}

Nosso objetivo neste artigo é analisar a constituição do discurso formal no contexto do Tribunal do Júri, a fim de delimitar parâmetros que o caracterizem com base nos discursos de Promotores de Justiça e de Advogados de Defesa. O contexto foi escolhido em razão de nesse ambiente serem realizados diversos ritos processuais e, principalmente por essa razão, ele foi identificado como formal. A pesquisa é fundamentada na

1. Pós-doutora pela Unicamp, com doutorado e mestrado em Linguística pela UnB. É especialista em Língua Portuguesa e em Língua Inglesa e literatura angloamericana pela UFPI. Atualmente, é professora adjunta da UnB e coordenadora do curso de Letras Português (diurno).

2. Mestre em Linguística pela UnB. Graduado em Letras Português, também pela UnB, é Professor de Redação e Texto, além de Revisor de Gabinete de Ministro no Superior Tribunal de Justiça. 
Sociolinguística Interacional, com orientações etnográficas, combinadas com a metodologia da Análise da Conversação. O corpus é constituído de filmagem de uma sessão de julgamento no Tribunal de Justiça do Distrito Federal e dos Territórios, compreendendo aproximadamente onze horas de gravação.

Palavras-chave: formalidade; discurso jurídico; tribunal do júri.

\section{Introdução}

No Tribunal do Júri, as relações que ocorrem se baseiam na tentativa de firmar determinado entendimento. $\mathrm{O}$ objetivo central do artigo é analisar a constituição do discurso formal no contexto do Tribunal do Júri, a fim de delimitar parâmetros que o caracterizem com base nos discursos de Promotores de Justiça e de Advogados de Defesa. Segundo consta da lei que regula o desempenho do Ministério Público, no âmbito do Direito Penal, sua função é pela defesa da ordem jurídica e dos interesses da sociedade e pela fiel observância da Constituição Federal. Nesta, em seu art. 5, LVII, prevê-se que "ninguém será considerado culpado até o trânsito em julgado de sentença condenatória”.

Para isso, é que a todos é assegurado o direito da ampla defesa e do contraditório até que a sentença transite em julgado. Além, então, do Ministério Público, representado pelo Promotor de Justiça, e do Advogado de Defesa, o Tribunal do Júri é composto de sete jurados, os quais serão responsáveis pela condenação ou absolvição de quem é acusado. Com isso, todo o discurso dos envolvidos por acusar ou defender o réu deve voltar-se a esses que compõem o júri. O juiz (doravante J), por sua vez, dirige a sessão, com o intuito de manter a ordem e garantir que haja plena aplicação de todos os ritos processuais. Ainda, cabe a ele estabelecer, em caso de condenação do réu pelo Conselho de Sentença, a pena a que o acusado estará sujeito.

Para, então, analisar a constituição do discurso formal de Promotores de Justiça (doravante PJ) e de Advogados de Defesa (AD), inicialmente apresentaremos a metodologia utilizada na pesquisa, bem como a teoria de que nos utilizaremos para interpretar os dados. Em 
seguida, analisaremos a constituição da formalidade no Tribunal do Júri (TJ) e proporemos alguns parâmetros para caracterizar o discurso formal com base no contexto pesquisado e, para facilitar a análise dos dados da pesquisa, disponibilizamos o quadro abaixo com os nomes dos réus, de algumas testemunhas $(\mathrm{T})$ e de outras pessoas envolvidas no processo, constantemente citadas durante o julgamento, com suas respectivas funções ${ }^{3}$.

\begin{tabular}{|c|c|}
\hline Nome & Função \\
\hline Manoel & Vítima \\
\hline Rafael & Réu \\
\hline Kleber & Réu \\
\hline Gustavo Silva & $\begin{array}{l}\text { Gerente de uma das filiais do Dinner (restaurante da } \\
\text { vítima) }\end{array}$ \\
\hline Pedro Marques & $\begin{array}{l}\text { Sócio da vítima no restaurante Dinner, do qual Gustavo } \\
\text { Silva era gerente. }\end{array}$ \\
\hline Cláudio Cabral & $\begin{array}{l}\text { Testemunha (T1) de acusação. Passava de carro na pista } \\
\text { momentos antes de ocorrer o crime. }\end{array}$ \\
\hline Caio & Sobrinho do acusado Rafael \\
\hline Walter & Sobrinho do acusado Rafael \\
\hline Ricardo & $\begin{array}{l}\text { Testemunha (T3) de acusação e de defesa (neutra). Policial } \\
\text { Civil que atuou na investigação do crime. }\end{array}$ \\
\hline Maria & Testemunha (T5), irmã do acusado Rafael \\
\hline
\end{tabular}

\section{O caso em análise: metodologia}

Este trabalho tem como princípio investigar a língua em uso. Assim, é importante utilizar-se da pesquisa qualitativa, que objetiva compreender os significados das ações dos sujeitos nas interações das quais participam. O motivo central da escolha da pesquisa qualitativa

3. Como será exposto adiante, trata-se de nomes fictícios, para preservar a identidade dos sujeitos da pesquisa. 
baseia-se no fato de que nela é possível averiguar os acontecimentos da vida real, a interação livre. Assim, não foram utilizados questionários estruturados, visto que esses poderiam afastar as ações ocorridas de forma espontânea, carregadas de informações que direcionam a interação social.

\subsection{A coleta de dados: da etnografia à etnometodologia}

Para a coleta de dados, utilizamo-nos das contribuições da Etnografia da Comunicação. A principal característica da etnografia da comunicação está na natureza dos significados - interligados às crenças partilhadas e aos valores adquiridos pela comunidade - dependentes dos contextos social e cultural. Assim, o objetivo de Hymes e Gumperz - quando a criaram, na década de 60 - era investigar o significado social, a diversidade de práticas envolvidas e o uso real da língua em contextos específicos. Com isso, a intenção da etnografia da comunicação não é apenas descrever os contextos como eles se apresentam, mas interpretá-los. Consoante Magalhães (1994, p.202), em pesquisa etnográfica é possível negociar e construir, entre o pesquisador e o colaborado, o conhecimento, o que possibilita desmistificar visões distorcidas ou escondidas pelo senso comum. Ou seja, há reconstrução das práticas sociais, dos significados sociais.

Para que sejam contemplados esses aspectos, é aconselhável a utilização, segundo Duranti (1997, p.98), de filmagens e gravações de áudio, além de outras ferramentas como anotações, que permitam analisar o conjunto de formas produzidas pelos interagentes. Os discursos do PJ e do AD serão transcritos consoante a Etnomedologia e a Análise da Conversação. ${ }^{4}$

A etnometodologia constitui uma corrente da sociologia americana desde 1967, com a publicação, na Califórnia, do livro Studies in Ethonomethodology (Estudos em Etnometodologia) de Harold Garfinkel. De modo geral, trata-se de uma abordagem

4. Anexo, no final deste artigo, há o quadro da convenção das transcrições. 
teórico-metodológica que estuda, a partir de determinados princípios e métodos, como os interagentes organizam a interação,

A partir dos estudos da etnometodologia, surge a Análise da Conversação (doravante $\mathrm{AC}$ ), a qual será utilizada neste trabalho a fim de explicitar os elementos que permeiam a interação, sustentando o funcionamento das trocas comunicativas. De acordo com Hutchby e Wooffitt (1998, p.14), a AC objetiva "descobrir como os participantes compreendem e respondem um ao outro em seus atos de fala, com um foco central em como sequências de ação são geradas”.

No Tribunal do Júri, as falas são concedidas pelo Juiz, que preside a sessão. No entanto, em diversos momentos os turnos de fala são assaltados, tanto pelo PJ quanto pelo $\mathrm{AD}$ em momentos que são chamados de aparte. Em tese, esse serve para que se possa fazer alguma observação ou correção no discurso alheio. Entretanto, como será discutido adiante, ele serve, na prática, como meio para confundir a outra parte e até mesmo forma de discussão acerca de outro assunto. Esclarecemos, por fim, que o Tribunal do Júri é composto de cinco partes: inquirição de testemunhas; inquirição do acusado; exposição da acusação; exposição da defesa; resultado do julgamento.

\subsection{A pesquisa em campo}

A pesquisa foi realizada em junho de 2011, no Tribunal de Justiça do Distrito Federal e dos Territórios, na Circunscrição de Brasília. Participavam da sessão de julgamento: um juiz de Direito; um promotor de justiça; dois assistentes de acusação; um advogado de defesa (particular); um assistente de defesa; sete jurados; dois réus; dez testemunhas; dois oficiais de justiça; cinco policiais militares, sendo três do Distrito Federal e dois do Estado de Goiás; e uma secretária do Tribunal.

$\mathrm{O}$ caso em análise consiste no julgamento de dois policiais militares do Estado de Goiás, que foram acusados de cometerem o homicídio de um importante empresário que possuía diversos 
restaurantes no País. Segundo a acusação, eles foram contratados pelo gerente de uma das filiais - que já fora condenado a mais de 20 anos de prisão, em 2009 - para que o ajudassem na execução de Manoel. Ainda de acordo com a acusação, os réus e o outro acusado aproveitaram a vinda da vítima a Brasília, local onde também tinha uma filial de seu restaurante, para efetuar o crime. Os réus negavam a acusação e trouxeram como possível álibi a participação na hora do crime em uma palestra na faculdade que frequentavam nesse período. Dez testemunhas foram ouvidas, sendo que duas eram da acusação, uma de ambas as partes e seis, portanto, da defesa. Salientamos, ainda, que além do crime de homicídio, os réus responderam concomitantemente ao crime de roubo do celular da vítima. Isso significa que, como há conexão entre os crimes, coube aos jurados julgarem tanto o homicídio quanto o roubo.

Utilizamos, na sessão de julgamento, câmera filmadora e anotações. No auditório há uma parte reservada para a imprensa, local em que as câmeras ficam. A nossa permaneceu, portanto, nesse ambiente, o qual dista do tablado onde estavam os interagentes cerca de vinte e cinco metros. A sessão de julgamento teve duração de aproximadamente dezesseis horas (iniciou-se às $10 \mathrm{~h}$ e terminou às $3 \mathrm{~h}$ da manhã). Retirados alguns momentos em que não havia interação, foram analisadas cerca de onze horas de gravação.

Os colaboradores foram informados da pesquisa logo antes de iniciarem a sessão de julgamento. Antes, apenas o juiz do Tribunal do Júri, presidente da sessão, tinha conhecimento deste trabalho. Logo que todos participantes souberam, foram-lhes comunicado, de modo geral, os objetivos desta pesquisa. Ainda, para que autorizassem a filmagem de suas ações, o Promotor de Justiça e o Advogado de Defesa, e seus respectivos assistentes, assinaram o Termo de Consentimento Livres e Esclarecidos (TCLEs) e o Termo de Cessão de Uso de Imagem (TCUI), termos nos quais contêm as informações relevantes sobre a metodologia utilizada, o objetivo da pesquisa e a ressalva de que dela poderiam desistir de participar a qualquer instante. Esse procedimento é exigência do Comitê de Ética da Universidade de Brasília para pesquisas que envolvam seres 
humanos. Registramos que houve a devida regulamentação deste trabalho por esse órgão no mês de junho de 2011.

Destacamos que a divisão dos excertos, bem como sua respectiva numeração, foi feita conforme a ordem cronológica dos acontecimentos da sessão de julgamento. O discurso transcrito em E3, por exemplo, ocorreu depois do E2. Em alguns casos, esses excertos aparecem subnumerados, visto que retiramos do excerto um exemplo para explicitar determinado assunto. Isso pode ser observado em E15.1, por exemplo, em que subtraímos uma parte do excerto 15, a fim de explicitar determinado aspecto.

\section{A interpretação dos dados: a Sociolinguística Interacional}

A sociolinguística interacional investiga como o processo interpretativo funciona nas interações interpessoais, utilizando enunciados reais dos usuários da linguagem na comunicação face a face. Dessa forma, em razão de este trabalho buscar analisar a constituição da formalidade no discurso de promotores e de advogados de defesa, no contexto do Tribunal do Júri, as observações serão feitas a partir do que propõe essa abordagem da sociolinguística.

A sociolinguística interacional surge em meados dos anos 70 , proposta por John Gumperz. Baseia-se em conceitos da Antropologia, da Sociologia e da Linguística. Nesse sentido, busca analisar a organização do discurso e da interação social em encontros face a face, pois há constantemente, nessas situações, sustentação de mensagens que orientam a conduta de participantes e atribui-se significado à atividade desenvolvida. Segundo Figueroa (1994, p.98), as palavraschave para definir a Sociolinguística Interacional são: intencionalidade (baseada em regras e convenções sociais); interpretação (partilha de conhecimentos e negociação de significados e de intenções); significado social (entendimento do que está se passando por parte dos interagentes). 


\section{O discurso formal}

Há poucos estudos que analisam o discurso formal e o informal e, ainda, em alguns entre esses, inexiste explanação clara do que vem a ser a formalidade. Ervin-Tripp (1972, p.235) afirma que a formalidade requer posicionamento sério, polido e respeitoso em cada situação social. Atkinson (1982) analisa a formalidade sob o enfoque da etnometodologia e de análises conversacionais. Segundo esse autor, os elementos que caracterizam a formalidade são: a frequência de pausas nos turnos; troca de turnos; tópicos em discussão; a categorização de pessoas; objetos e eventos que são selecionados e usados pelos falantes; as hesitações; e a mudança de ações dos participantes que estão inseridos na conversa. Além disso, esse mesmo autor defende que a formalidade ainda pode ser relacionada à noção de nervosismo, no sentido de que quanto mais relaxada estiver a conversa mais informal ela é.

Por outro lado, Ochs (1979) define os discursos formal e informal como relativamente planejado e relativamente não planejado, respectivamente. A autora afirma que discurso relativamente não planejado é o que não tem premeditação e preparo de sua organização da organização, ao passo que discurso relativamente planejado é o que é pensado e organizado antes de ser produzido. Argumenta, ainda, que os discursos mais planejados são aqueles cujos atos são previstos em toda a sua forma, enquanto os discursos menos planejados são aqueles nos quais somente certos atos são previstos no curso de sua produção.

Em seu artigo Formality and Informality in Speech events, Irvine (1978, p.212-213) apresenta revisão bibliográfica do tema e discute três vertentes sobre como diversos autores tratam da noção de formalidade/informalidade. Consoante isso, Irvine (1978) sugere que o par formalidade/informalidade está ligado a aspectos culturais. Nessa perspectiva, a autora apresenta quatro aspectos que, além de aparecerem envolvidos com os elementos discursivos e situacionais da formalidade, encontram-se distribuídos em dois grupos, concernentes ao código e à situação, conforme sintetizamos na Tabela 1 . 


\begin{tabular}{|c|c|}
\hline Concernentes ao código & Concernentes à situação \\
\hline $\begin{array}{l}\text { 1. Estruturação desenvolvida e } \\
\text { previsibilidade quando da produção } \\
\text { linguística. Analisam-se a entonação, } \\
\text { a fonologia, a sintaxe, itens lexicais, } \\
\text { turno de fala entre outros. }\end{array}$ & $\begin{array}{l}\text { 1. A identidade social dos participantes é } \\
\text { o foco. Se há uma relação já prévia entre } \\
\text { os falantes, a tendência é que haja maior } \\
\text { entrosamento e, consequentemente, } \\
\text { maior informalidade. }\end{array}$ \\
\hline $\begin{array}{l}\text { 2. Consistência dos significados das } \\
\text { variantes. Envolve regras existentes. } \\
\text { Há elementos mais consistentes (em } \\
\text { oposição à ironia). Em ambientes } \\
\text { mais formais, co-ocorrem regras mais } \\
\text { restritas, o que ocasiona significados } \\
\text { lexicais e sintáticas mais consistentes. }\end{array}$ & $\begin{array}{l}\text { 2. Há diferença entre conversas com } \\
\text { grandes grupos e as que ocorrem } \\
\text { com duas pessoas. Em conversas } \\
\text { que ocorrem entre várias pessoas } \\
\text { há a tendência de surgirem diversos } \\
\text { assuntos que coocorrem, ao passo } \\
\text { que, quando a conversa se dá entre } \\
\text { apenas duas pessoas, o assunto é mais } \\
\text { focalizado. }\end{array}$ \\
\hline
\end{tabular}

(adaptado de Irvine 1978, p.212-213)

Uma observação se faz, aqui, necessária. Trata-se do primeiro elemento à direita da Tabela 1 acima destacada, dentro do marco concernente à situação. Resulta que não abordamos a identidade como categoria fixa e inerente aos sujeitos, como sugere Irvine (1978) em seu artigo - até mesmo porque, como afirma Castells (1999), nesse caso, o conceito de identidade guarda relação com papel social. A identidade neste trabalho é vista como dinâmica, assim como a enuncia Bauman (2005) e Castells (1999), no sentido de ser fluida e, sobretudo, constantemente negociada no curso da interação. Ou seja, ao passo que o papel social possui caráter estável, a identidade é alterada de acordo com as negociações estabelecidas no curso da interação. Por isso, a identidade servirá como parâmetro para delimitar formalidade. Afirma Irvine (1978, p.216) que os aspectos que sumarizamos na tabela acima tendem a ocorrer conjuntamente, mas não sempre. A autora considera que esses quatro aspectos possuem aplicação universal. Ela ressalta que esses elementos poderão coocorrer, mostrando graus de formalidade, o que se assemelha a um continuum.

Além de utilizar as contribuições de Irvine, nesta pesquisa ainda contemplaremos as análises de Brandão (1997) acerca do tema. Essa 
autora estabelece parâmetros que nos serão úteis para nossas análises. Segundo Brandão (1997, p.26), há três vertentes que podem ser utilizadas: vocabular - a escolha lexical; fonológica - supressão de fonemas, diferenças de pronúncias; e sintática - estruturas sintáticas e truncamento sintático.

\section{Análise dos dados e reflexões}

De acordo com a transcrição dos dados, localizamos três aspectos que podem nos mostrar como se constitui a formalidade no discurso do PJ e do AD. São eles: (i) a variação estilística de acordo com a audiência; (ii) a cinésica; e (iii) a frequência da troca de turnos. Apresentaremos, portanto, em seguida, e de forma pormenorizada, esses aspectos. Depois, delimitaremos os parâmetros que podem caracterizar o discurso formal e o informal.

É relevante esclarecer que o Tribunal do Júri é composto de diversos ritos processuais, no sentido de que os turnos de fala são concedidos pelo Juiz e o tempo de fala é delimitado e, em alguns momentos, é planejado. Os trajes são apropriados para a situação, visto que há toga própria para o PJ, outra para o $\mathrm{AD}$ e, ainda, outra para o Juiz; elas são diferenciadas por cores. Há, ainda, alguns elementos linguísticos tidos como fundamentais nesse contexto, como os pronomes de tratamento. Ainda, a maior parte, senão todos interagentes do Tribunal do Júri, possuem alto grau de letramento. ${ }^{5}$

Com todos esses elementos, esperávamos, antes de sair a campo, que o discurso do PJ e do AD fosse primordialmente formal. Entretanto, como discutiremos mais adiante, o discurso formal é utilizado como estratégia em relação ao Conselho de Sentença, a depender do que se objetiva.

5. Referimo-nos ao PJ, AD e J. Os jurados devem, segundo a lei que regulamenta o Tribunal do Júri, ter no mínimo o ensino médio concluído. 


\subsection{Variação estilística de acordo com a audiência}

Como sugere Van Dijk (1998, p.79), o estilo de fala é recurso estratégico na interação humana. Nesse sentido, haverá variação de estilo de acordo com aquele a quem se dirige o discurso. Desse modo, apresentaremos, a seguir, a inquirição de testemunhas e, em seguida, a sustentação oral, que é voltada para os jurados.

\subsubsection{A inquirição de testemunhas}

$\mathrm{Na}$ inquirição das testemunhas, a intenção tanto da defesa quanto da acusação é esclarecer alguns fatos que podem ser reveladores para os jurados. Portanto, cada ação do PJ ou do AD é voltada estrategicamente para expor ou esconder determinados aspectos do processo. Dessa forma, é importante o PJ ou o AD estabelecer com a testemunha, mesmo sendo ela contrária à tese defendida por algum deles, algum vínculo. É nesse instante que o aspecto ora em análise surge. Vejamos o seguinte excerto:

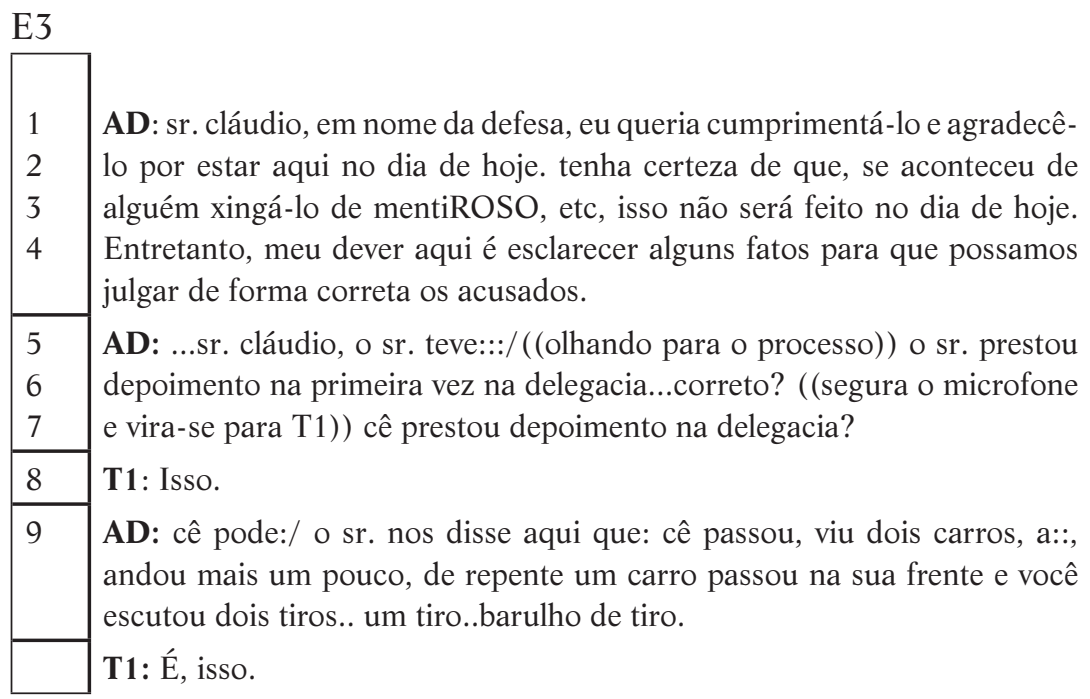


No trecho acima, o AD inicia sua inquirição com uma testemunha que era de acusação. O discurso é primordialmente mais formal em sua primeira fala. Utilizando os critérios de Irvine (1978) e Brandão (1997), percebemos isso, uma vez que o AD recorda à testemunha o fato de que quando essa esteve no julgamento do outro acusado, em 2009, fora xingado, mas, na tentativa de salvar a própria face, promete à testemunha que isso não ocorreria novamente (linha 3). $\mathrm{O}$ AD escolhe palavras menos comuns, como a conjunção entretanto (linha 3) - em oposição a mas -, corroborando ao que Brandão (1997, p.26) afirma. Depois de cinco segundos, o AD inicia sua inquirição. Logo na primeira enunciação dele, percebemos truncamento sintático: ele inicia a oração com o Senhor teve (linha 5) e não dá continuidade a esse enunciado; ao contrário, passa para outra estrutura, o senhor prestou. Demonstra o AD um discurso que está sendo planejado naquele instante, que está sendo construído na interação. Exatamente por isso o AD repete a frase prestou depoimento na delegacia. Ainda, apresenta variação no vocábulo você, em "cê" (linha 7). Essa é uma das características do discurso informal, também conforme Brandão (1997, p.26). O AD apresenta essas mesmas características em sua terceira fala: variação e truncamento sintático (cf. linhas 9-11).

Chamamos a atenção, ainda, para a presença do primeiro aspecto de formalidade concernente à situação - identidade - proposto por Irvine (1978), visto na seção 4. Isso porque, assim como afirma essa autora, o discurso tende a ser mais formal quando os interagentes não apresentam prévio relacionamento entre si. Desse modo, acreditamos que um dos motivos que possa ter contribuído para a maior formalidade entre o AD e essa testemunha é a ausência de conhecimento prévio entre esses interagentes.

Ressaltamos, por fim, a estratégia de envolvimento ${ }^{6}$ de que se utiliza o AD. Ele, ao se voltar para as testemunhas - diferentemente do que ocorre com os jurados, como será visto adiante - varia seu estilo, utilizando-se de discurso com traços de informalidade. Isso pode

6. Para saber mais acerca de estratégia de envolvimento, vide Dissertação de Melo (2011), Discurso Formal no Tribunal do Júri: estratégias argumentativointeracionais. 
ser compreendido como estratégia para envolver a testemunha, com o intuito de evidenciar que não há relação assimétrica entre eles, de que estão no mesmo nível hierárquico, inexistindo, assim, a intenção de persuadir o interlocutor, havendo apenas pretensão de estabelecer vínculo de confiança para obter a colaboração da testemunha.

\subsubsection{A sustentação oral - voltada para os jurados}

Após a inquirição das testemunhas e dos acusados, cabe ao PJ e ao AD apresentarem suas teses. No trecho seguinte, há o início da fala do AD em sua sustentação oral. Depois de cumprimentar todos os interagentes nominalmente e apresentar-lhes elogios, ele volta seu discurso para os jurados:

\section{E18}

1 AD: ((em pé, olhando para os jurados. gestos contidos.))/.../ por fim, 2 cumprimento o conselho de sentença, que tem a tarefa de julgar hoje 3 duas pessoas, que estão aqui peDINDO a imparcialiDADE dos srs., a 4 aNÁLIse das provas. os srs. não vieram AQUI NEM para condenar e 5 nem para absolver. a missão maior dos srs. é que VEjam ( ), promovam 6 a pacificação social e promovam também, sobretudo, a justiça. portanto, 7 como paTRONO dos dois acusados, venho pedir a atenção e também 8 o espírito que esteja despido de qualquer preconceito, pré-julgamento 9 e que OUçam de forma atenta, mesmo depois de mais de dez horas de 10 julgamento. também estou cansado, acordei às quatro da manhã pra estar aqui, pra apresentar a tese a vocês. e que o srs., de forma soberana, possam decidir a partir das provas nos autos ((o discurso foi dito de maneira bastante pausada)).

De acordo com Irvine (1978, p.79), há dois aspectos a serem observados no discurso concernentes ao código: a sua elaboração assim como também observa Brandão (1997, p.26) - e a significação das palavras utilizadas. No que diz respeito ao primeiro, o AD apresenta estruturas oracionais completas, com sujeito, verbo e complementos. Também não há truncamentos no excerto em análise. Além disso, há nesse discurso progressão temática, visto que é apresentado primeiro o porquê de os jurados estarem ali presentes, em seguida, o AD 
argumenta como deve ser feito o julgamento e, por fim, deixa implícito - na linha 10 - que os jurados devem ser coerentes com o que está nos autos. De acordo com Gumperz (1997, p.44), a inferência conversacional resulta da análise de elementos que conduzem à determinada interpretação, surgindo com natureza sugestiva . Nesse sentido, infere-se que o objetivo do $\mathrm{AD}$ é afirmar que não há provas robustas - como ele mesmo depois sustentará - e que, assim, os réus seriam inocentes.

Já no que se refere ao segundo aspecto descrito por Brandão (1997, p.26) - significação das palavras -, o AD se utiliza de palavras que estão empregadas, em sua maior parte, no sentido denotativo, ou seja, com significados mais delimitados. Brandão (1997, p.26), na vertente vocabular apresentada, discute outro aspecto para caracterizar o discurso formal: a escolha cuidadosa das palavras em vez do emprego de palavras de sentido genérico, que denotariam discurso com traços de informalidade. Percebemos isso quando o AD escolhe o vocábulo patrono (linha 6), no sentido de que traduz com precisão a função do advogado na situação em análise. É evidente também o planejamento no discurso do $\mathrm{AD}$, visto que é enunciado de maneira bastante pausada.

Frisamos, por fim, que um dos motivos para que haja mais traços de formalidade no discurso analisado é o tipo de identidade negociada. Diversamente do que foi discutido acima - quando o AD conversava com as testemunhas, adotando o estilo com maiores traços de informalidade -, na interação com o júri, o AD tenta negociar identidade institucional, ou seja, a identidade de alguém competente, que conhece o que fala. Por isso, então, o discurso apresentou maiores traços de formalidade.

\subsection{Cinésica}

Segundo Birdwhistell (1985), antropólogo americano pioneiro no estudo da cinésica, trata-se de uma categoria interacional que corresponde aos gestos e aos demais movimentos corporais desenvolvidos na interação humana. Afirma o referido autor que há 
íntima ligação entre o contexto em que ocorre a interação e a cinésica. No contexto em questão, a cinésica é indicativa de formalidade. Isso, porque, em diversos momentos em que os interagentes proferiam seus discursos, os gestos aumentaram consideravelmente quando havia mais traços de informalidade, diminuindo na mesma proporção com a incidência de traços formais.

Em E18, os gestos estavam contidos, coerente a um discurso com prevalência de traços de formalidade. Já em E21, o AD, ainda em sua sustentação oral, continua com traços de discurso formal, entretanto, quando é interrompido pelo PJ, que assalta o seu turno, os gestos aumentam consideravelmente.

\section{E21}

1 AD: /.../ ( (a mão esquerda está no bolso. apenas há gestos contidos com

2 a mão direita)) srs., a partir desse momento=a partir desse momento, em

3 que houve a identificação dos acusados gustavo, rafael e kleber, a busca e

4 apreensão ( ), "tenho o reconhecimento", ou seja, tenho a AUTORIA,

5 que eu falei pro srs. a polícia estava a todo momento buscando a autoria

6 e quem concorreu pra autoria. "OLHA, encontramos". "já sabemos que

7 o telefone estava em posse deles"

8 PJ: [posse de quem, dr.?

9 AD: (( retira a mão do bolso)) em posse de gusta/ de rafael e em posse de

10 kleber ((apontando para os acusados e aproximando-se do PJ)).

11 PJ: então isso aí o sr. já aceita como verdadeiro?

12 AD: o quê?

13 PJ: que o telefone estava na posse do rafael?

14 AD: ((vira-se para os jurados, volta-se em seguida para o PJ. os gestos com as mãos aumentam)) pelo menos é o que está dizendo a acusação, não é? ((cruza os braços $)) / . . . /$

Em E21, o AD, em sua primeira fala, estava tratando do assunto de que T2 havia identificado um dos réus com apenas duas fotos. Isso, segundo defende, teria gerado imprecisão no processo de reconhecimento dos acusados. Além disso, assegura que, após o reconhecimento por somente essa testemunha, não houve maiores investigações em busca de possíveis outros envolvidos. O AD cita, então, falas que representariam o que pensou ou o que disse à 
Polícia (linha 3-6). Durante toda essa exposição seus gestos eram extremamente contidos, sendo que uma das mãos estava no bolso, o que demonstra sua rigidez ao fazer sua sustentação oral.

Salientamos, por oportuno, que o telefone na linha 5 é um aparelho de celular que era da vítima e que fora encontrado com o acusado Rafael, o que, segundo a acusação, constitui prova cabal da culpabilidade dos réus. Quando o $\mathrm{AD}$ assevera Já sabemos que o telefone estava em posse dos acusados (linha 5), o PJ, por não estar no mesmo frame que o AD - porquanto estava lendo o processo e conversando com o J - interrompe-o, pensando que aquele tivesse afirmado que quem sabia que o celular seria dos acusados seria a própria defesa.

A partir dessa interrupção, o $\mathrm{AD}$ retira a mão do bolso, aproxima-se do PJ e gesticula reiteradamente ao ponto de cruzar os braços. Destaco também que é, a partir do momento dessa intervenção do PJ, que há o primeiro truncamento na fala do $\mathrm{AD}$, na linha 8 , o que revela alternância nesse ponto para o estilo informal. Noutras palavras, a partir da mudança de frame, houve a exigência de um novo footing, ou seja, o AD mudou o seu alinhamento em relação ao PJ para se referir a ele.

\subsection{A frequência da troca de turnos}

Nas seções do TJ, o turno de fala, em tese, é concedido pelo J ao PJ e ao AD. No entanto, na inquirição, exatamente por essa atividade se caracterizar pelo formato de pares adjacentes do tipo pergunta $e$ resposta, é comum haver com maior frequência troca de turnos. O que ressaltamos é que a intensa troca de turnos propicia ocorrência de truncamentos, mais hesitações, ocorrência de supressão de fonemas em palavras, entre outros elementos. Dessa maneira, o que acontece é uma interação sem regras predefinidas, na qual há constante assalto de turno, principalmente pelo PJ - que é quem, nesse caso da inquirição, concederia a palavra à testemunha. No trecho seguinte, o PJ inquire T8 - colega de profissão e de faculdade dos acusados. 


\section{E15.1}

1 PJ: /.../ DEIXA eu perguntar pro sr. ((olha rapidamente para o processo, que está em 2 sua mesa)): o sr. disse que tava com o sargento rafael nesse curso. cê se lembra qual era 3 a palestra que estava sendo ministrada?

4 T8: tava tendo a palestra/ eram várias PALEStras destinados a TOdos acadêmicos. nós 5 estávamos assistindo sobre a: lei pelé.

$6 \quad$ PJ: sobre a lei pelé? O sr.=sr. foi com o sargento rafael e com quem mais?

$7 \quad$ T8: $\downarrow$ num entendi a pergunta.

$8 \quad$ PJ: quem mais que assistiu à palestra lá?

9 T8: ué, o resTANTE da turma.

10 PJ: o sr. lembra do nome de alguém?

11 T8: ah, tem vários = vários/ tem vários alunos.

12 PJ: o sr. sentou bem do lado dele assim ((faz gestos representando))? ele de um lado e 13 o sr. do outro?

14 T8: não necessariamente do lado, assim

15 PJ: [lá=lá o sr. disse que eram várias pessoas

16 T8:

[várias

17 pessoas

18 PJ: [eram=eram TODOS os cursos juntos? ((gestos circulares))

19 T8: era. TODOS os cursos juntos.

20 PJ:

[[juntos. então era um auditório grande?

21 T8:

[auditório grande

22 PJ:

[[grande. E o sr.

23 sabe dizer onde o sargento rafael sentou nesse auditório, já que não tava no lado do sr.?

24 T8: não, tava no e::: e:: durante a semana

25 PJ:

[ um minutinho, a pergunta é CLARA

26 T8:

[se o sr. deixar

27 PJ:

[ o sr. disse que ele não sentou

28 do seu lado. você sabe onde ele sentou?

29 T8: não tem como afirmar onde ele sentou, não.

30 PJ: tá, e:

31 T8: [faz três anos

32 PJ: [ E a pergunta que eu faço na sequência: cê sabe dizer, você tá falando $22 \mathrm{~h}$, cê

33 sabe dizer até que horas que ele permaneceu, ou o que leva o sr. afirmar que ele 34 permaneceu até às $22 \mathrm{~h}$ lá?

35 T8: $\quad$ [porque era o período: que durava a palestra.

36 PJ: [NÃO, a pergunta não=não

37 explica. por que que o sr. garante que ele permaneceu até às $22 \mathrm{~h}$ ?

38 T8: $\quad$ [num falei que garantia

39 PJ: ah bom! ((aproxima-se do encosto da cadeira. até então estava longe dele, mais 40 próximo do microfone)) então o sr. não garante que ele permaneceu até às $22 \mathrm{~h}$ ? 
Essa conversa entre o PJ e uma testemunha de defesa é bastante reveladora. O PJ se utiliza de estratégia argumentativo-interacional que definimos como inquirição acelerada. ${ }^{7}$ Isso porque ele interroga a testemunha de modo bastante rápido e recorrente acerca de um mesmo assunto - no exemplo em comento, a presença dos acusados ou não em uma palestra, que, segundo a defesa, ocorreu na mesma semana do crime, o que lhes serviria de álibi. Destacamos que, por ser uma inquirição, na qual há perguntas muitas vezes imprevistas, há a maior chance de ocorrerem traços de informalidade no discurso. Isto é, em pares adjacentes, do tipo pergunta e resposta, o planejamento no discurso é menor e assim propicia maiores ocorrências de truncamentos, repetições, supressões, entre outros traços que conferem informalidade ao discurso. Quando então essa inquirição se dá de maneira bastante acelerada, como no exemplo ora em análise, esses traços de informalidade aumentam substancialmente, visto que o tempo para se planejar o discurso diminui consideravelmente.

Nesse sentido, os turnos de fala, apesar de serem conduzidos pelo PJ, são constantemente alterados. Tem-se supressão fonológica tanto do PJ (linha 2) em cê, quanto de T8 em tava (linha 4). Além disso, na linha 4, T8 apresenta truncamento sintático em Tava tendo a palestra e não prossegue seu raciocínio, iniciando outra oração, eram várias palestras. Na linha 9, T8 apresenta interessante elemento: ué. De acordo com Houaiss (2003 - versão eletrônica), essa expressão “exprime espanto, pasmo, surpresa, admiração, por vezes irritação". No enunciado em questão, surge como irritação de algo que, como queria fazer entender a testemunha, seria óbvio. Essa expressão ocorre primariamente em discursos informais. Na linha 10, ainda na vertente que concerne ao código (Brandão 1997; Irvine, 1978), o PJ apresenta estrutura que vai de encontro ao que recomenda a norma culta: o uso do verbo lembrar com o pronome integrante, em O Sr. lembra do nome de alguém? (em oposição a $O$ Sr. se lembra[-se] do nome de alguém) ${ }^{8}$.

7. Esta estratégia é amplamente discutida no trabalho de Melo (2011).

8. Segundo Celso e Cunha (2008, p.539), a construção - ou seja, sem o pronome e com a preposição $d e$ - feita pelo PJ é "considerada viciosa pelos gramáticos, mas muito frequente no colóquio diário dos brasileiros”. 
Já na linha 14, T8 utiliza o assim como marcador discursivo, para expressar imprecisão ou dúvida do que será afirmado em seguida, caracterizando um discurso sem prévio planejamento, propício ao surgimento de traços de informalidade. A propósito, ressalte-se, na linha 25, o uso do diminutivo (minutinho). Como bem observa Brandão (2010, p.38), o sufixo -inho pode caracterizar, entre outros sentidos, ironia, sendo seu uso mais frequente em discursos informais.

Por outro lado, no trecho que se segue, o PJ, na sustentação oral, mantem o turno de fala apresentando menos traços de informalidade. Assume, pois, um discurso mais formal. Vejamos.

PJ: ((em pé, no local que lhe é reservado (à esquerda do J), com poucos gestos, uma das mãos está dentro do bolso)) agora vejam, vossas excelências: se eles com o mesmo espírito de farda, de coleguismo iam deixar "não, tortura, não, faz prova contra o cidadão". e vejam se a políCIA CIVIL de Brasília, se tivesse COM MÁ-FÉ, ia procurar justamente uma instalação MILITAR, pra FORJAR PROva, pra CRIAR ((vira-se para os réus)) PROva contra os::: acu::sados? NUNca. lá chegou, deu-se todas as OPORTUNIdades. A MÃE do rafael, o soBRINHO, o tal CAIO, a:quele garotinho, foram ouvidos na PRESENÇA de um advoGADO. foram ouvidos na presença de miliTA::RES do estado de goiás, que assinaram o TERMO. a soldada michele, o tenente, atestan:do a idoneidade das oitivas... fica a coisa MAIS viSÍVEL, - aqui pra vossas excelências, dizer que esses militares, que esse tenente, ia permitir uma criança ser forçada para criar uma prova contra um coLEGA de FARda.

Em que pese o uso de algumas supressões fonológicas, próprias do discurso informal, como na linha 3 - iam, em vez de iriam -, e da ausência de concordância verbal na linha 6 - deu-se todas as oportunidades, em detrimento a deram-se -, esse trecho apresenta maiores traços de formalidade. Isso porque, primeiro, o discurso está planejado, ou seja, inexistem nesse excerto marcas de truncamento sintático, omissões de termos; segundo, os pronomes de tratamento utilizado pelo PJ - Vossas Excelências, ao referir-se aos jurados; terceiro, os gestos são contidos, característica de discurso formal. 


\section{Considerações finais}

O discurso de Promotores de Justiça e de Advogados de Defesa é estratégico. Os traços de formalidade sobressaem no instante em que isso se torna importante aos locutores e aos interlocutores. Todos os elementos que envolvem um Tribunal (e consequentemente o do Júri) são bastante formais, principalmente devido aos ritos processuais. Isso possivelmente se refletiria no discurso dos envolvidos no Tribunal do Júri. No entanto, não é o que ocorre. A variação estilística é feita de acordo com os interesses dos interagentes. A partir desses aspectos e com base nos estudos de Irvine (1978), Ochs (1979) Atkinson (1982) e Brandão (1997), propomos os parâmetros abaixo que podem ser norteadores para caracterizar a formalidade no contexto pesquisado.

1. Elaboração do código: refere-se à estruturação adequada do código, segundo a norma culta da língua. Envolve, portanto, elementos fonológicos (como fonemas bem articulados), lexicais (predominância de vocábulos denotativos e ocorrência de itens eruditos) e sintáticos (ausência de truncamentos e realização de inversões sintáticas). Assim, quanto mais bem elaborado estiver esse código, mais formal o discurso tende a ser. Ainda quanto a esse aspecto, há o planejamento do discurso (Ochs 1979; Irvine, 1978). Ou seja, o discurso tende a ser mais formal quando há maior previsibilidade quando da sua execução.

2. Turnos conversacionais: trata-se da troca de turnos de fala, no sentido de que quanto mais trocas há, mais informal ele é. No discurso formal, o locutor tende a dominar o turno de fala.

3. Cinésica: a cinésica, considerada como categoria interacional, diz respeito aos gestos dos interagentes. A gesticulação tende a aumentar no discurso informal.

4. Negociação de identidade: a identidade que está sendo construída é fator que condiciona o uso de (in)formalidade. Assim, a partir da imagem que o locutor deseja obter de 
sua audiência, como sujeito estrategista, usará o seu estilo de fala de acordo com a identidade que estiver sendo negociada. Nesse sentido, identidades institucionais tendem a conferir maiores traços de formalidade.

5. Contexto situacional: o contexto físico também pode contribuir para o tipo de discurso a ser proferido. Isso porque o discurso formal tende a ocorrer em ambientes institucionais, quando os interagentes estão exercendo a identidade que esse contexto exige. Não basta o PJ estar dentro de um Tribunal; ele tem de estar exercendo sua identidade de promotor, e não de amigo, por exemplo.

Esses parâmetros, para delimitar formalidade, podem ser estabelecidos em um continuum, como exemplificado abaixo:

\section{Formalidade}

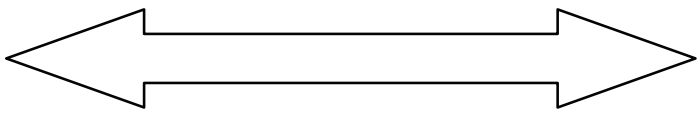

Ou seja, assim como apresentado por Irvine (1978), eles podem aparecer conjuntamente, mas não necessariamente. É por isso que mencionamos que são traços de formalidade. Exemplo disso ocorre no uso por parte tanto do PJ quanto do AD do pronome Vossa Excelência. Houve variação desse pronome e ele é utilizado amplamente apenas como Excelência. Possíveis motivos podem justificar essa variação linguística: o novo pronome é mais curto e, além disso, não tem de levar a oração que o segue para a terceira pessoa, o que gera maior facilidade ao locutor. Nem por essa variação em vários casos o discurso deixou de ser formal, razão pela qual, repetimos, o importante é falar em traço.

Recebido em: agosto de 2013 Aprovado em: setembro de 2013 cibelebo@uol.com.br wanderson.goncalves@stj.jus.br 


\section{Referências bibliográficas}

ATKINSON, J. M. The British journal of sociology. v. 13, n.1, mar, 1982. pp. 86-117.

BAUMAN, Z. Identidade: entrevista à Benedetto Vecchi. Rio de Janeiro: J. Zahar Editor, 2005.

BRANDÃO, C. Do discurso formal para o informal: um estudo de variação estilística no meio acadêmico. Dissertação de Mestrado. Universidade de Brasília: Brasília, 1997.

BRASIL. Constituição da República Federativa do Brasil. Congresso Nacional: Brasília, 1988.

BIRDWHISTELL, R.L. Kinesics and context: essays on body motion communication. 4.ed. Philadelphia: UPP (University of Pensylvania Press), 1985.

CASTELLES, M. O poder da Identidade. Vol 2. São Paulo: Paz e Terra, 1999. CUNHA, C.; CINTRA, L. Nova Gramática do português contemporâneo. $5^{\mathrm{a}}$ edição. Rio de Janeiro: Lexikon, 2008.

DURANTI, A. Linguistic Antropology. Cambridge: Cambridge University Press, 1997.

ERVIN-TRIPP, S. M. (1972). Alternation and co-occurrence. In J. J. Gumperz \& D. Hymes (Eds.), Directions in sociolinguistics: The ethnography of communication. New York: Holt, Rinehart and Winston, pp. 218-250.

FIGUEROA, E. Sociolinguistics Methateory. New York: Pergamon, 1994.

GARFINKEL, H. Studies in Ethnomethodology. Cambridge England: Polity Press, 1984.

GUMPERZ, J. Communicative Competence. In: COUPLAND, Nikolas and Jaworski (eds.). Sociolinguistics: a reader and coursebook. England: Palgrave, 1997.

HUTCHBY, I. \& WOOFFITT, R. Conversation Analysis: principles, practices and applications. USA: Blackwell Publishers Inc., 2001.

IRVINE, J. "Formality and Informality in speech events". In Sociolinguistic working paper. n. 52, Austin Texas, Southwest Development Laboratory, 21p. 1978.

MAGALHÃES, M.C.C. Etnografia Colaborativa e desenvolvimento do professor. Campinas (23), Jan/Jul, 1994. 
MELO, W. Discurso Formal no Tribunal do Júri: estratégias argumentativointeracionais. Dissertação de Mestrado. Universidade de Brasília - UnB: Brasília, 2011.

OCHS, E. Planned and unplanned discourse. In: GIVON, T. (ed). Syntax and semantics. Vol. 12, p.51-79. Discourse and syntax. New York. Academic Press, 1979.

VAN DIJK, T. A. Discourse as Social Interaction. In: Discourse Studies: A Multidisciplinary Introduction. v. 2: London: SAGE Publications, 1998. 


\section{ANEXO}

Convenções das transcrições

\begin{tabular}{|c|c|c|}
\hline OCORRÊNCIA & SinAL & EXEMPLO \\
\hline Nome dos participantes & negrito & PJ \\
\hline Entonação descendente & - (seta indicativa para baixo) & $\downarrow$ Num entendi a pergunta \\
\hline Entonação descendente forte & ? (ponto de interrogação) & Sobre a Lei Pelé? \\
\hline Pausa preenchida & Eh, ah, ahã & Ah, tem vários=vários \\
\hline $\begin{array}{l}\text { Micropausa; pausa de menos } \\
\text { de cinco segundos; pausa de } \\
\text { mais de cinco segundos }\end{array}$ & $\begin{array}{l}(.) \\
(. .) \\
(\ldots)\end{array}$ & $\begin{array}{l}\text { na primeira vez na } \\
\text { delegacia...Correto? }\end{array}$ \\
\hline Falas simultâneas & [[ (dois colchetes) & $\begin{array}{l}\text { T8:cursos juntos. } \\
\text { PJ: } \quad \text { [ [juntos }\end{array}$ \\
\hline Falas sobrepostas & [ (um colchete) & $\begin{array}{l}\text { T8: Não necessariamente } \\
\text { do lado, assim } \\
\text { PJ: [Lá=lá o } \\
\text { Sr. disse que eram várias } \\
\text { pessoas } \\
\text { T8: } \\
\text { pessoas }\end{array}$ \\
\hline Palavras ditas sem pausa & $=$ & duas $=$ duas pessoas \\
\hline ampliação de som vocálico & $\begin{array}{l}: \\
: \\
:\end{array}$ & carros, a::, andou \\
\hline Palavra dita de modo pausado & - & MESMO MÉ-DI-CO \\
\hline $\begin{array}{c}\text { Trecho que não compreendi no } \\
\text { discurso }\end{array}$ & ( ) (parênteses simples) & $\begin{array}{c}\text { no caminho ( ), um chega } \\
\text { às } 7 \text { h42 }\end{array}$ \\
\hline Ênfase/aumento do tom da voz & MAIÚSCULA & xingá-lo de mentiRoso \\
\hline Eliminação de trecho & /.../ & /.../ DEIXA eu perguntar \\
\hline Truncamento & / & $\begin{array}{l}\text { Cê pode:/ o Sr. nos disse } \\
\text { aqui }\end{array}$ \\
\hline Comunicação não verbal & (( )) (parênteses duplo)) & $((\mathrm{PJ}$ olha para o J)) \\
\hline
\end{tabular}

Fonte: Atkinson e Heritage (2006), Gumperz (1999) e Preti (2008). 